\title{
HIBRIDISMOS CONTEMPORÂNEOS NO AUDIOVISUAL: APROXIMACÕES ENTRE CULTURA E TECNOLOGIA NO PROGRAMA DE TV O MUNDO SEGUNDO OS BRASILEIROS*
}

\author{
Barbara Stefannie Paiva de MELO** \\ Universidade Metodista de São Paulo, São Bernardo do Campo, SP
}

RESUMO

O presente artigo visa a expor e a problematizar a questão do hibridismo tecnológico na televisão brasileira. Tomando como ponto de partida o conceito de hibridismo cultural, explorado por Néstor García Canclini e Peter Burke, nota-se que ele perpassa o campo antropológico. Com base nesse conceito, perguntamo-nos se a televisão, enquanto meio de comunicação que nasce fixo, perde essa característica ao longo do tempo. Traçaremos um breve panorama da história da TV e, para ilustrar o tema, utilizaremos, como exemplo, o programa "O Mundo Segundo os Brasileiros", cuja transmissão se iniciou na TV aberta, mas que hoje pode ser assistido tanto no Youtube, quanto no Netflix. É importante nos debruçarmos sobre tais transformações, pois indicam que a televisão acompanha as mudanças tecnológicas e a convergência das mídias.

Palavras-chave: hibridismo; tecnologia; audiovisual; televisão; convergência da mídia

\section{INTRODUÇ̃O}

Comunicação e cultura são processos interligados, pois cada sociedade transmite suas tradições, seus costumes, seus símbolos e seus rituais a partir da troca de informações.

A comunicação constitui um processo social e cultural, por isso, ela só se concretiza a partir da existência de interlocutores. De acordo com Wolton

\footnotetext{
* Trabalho apresentado no GT Comunicação Digital e Tecnologias do PENSACOM BRASIL 2016.

** Mestranda do Programa de Pós-Graduação em Comunicação Social da Universidade Metodista de São Paulo (UMESP). E-mail: barbara.sp.melo@gmail.com.
} 
(2011, p. 88): "A comunicação é o aprendizado da convivência num mundo de informação onde a questão da alteridade é central".

José Marques de Melo, em Teorias da Comunicação: paradigmas latino-americanos (1998), traz uma definição da cultura a partir de um viés comunicacional. Para isso, cita Edgar Morin, que entende a cultura da seguinte forma:

uma cultura constitui um corpo complexo de normas, símbolos, mitos e imagens que penetram o indivíduo em sua intimidade, estruturam os instintos, orientam as emoções. Essa penetração se realiza através dos mecanismos de projeção e identificação, fornecendo pontos de apoio à vida prática e à vida imaginária (MELO, 1998, p.186).

De acordo com Martino (2009, p. 54), ocorreu, ao longo da história, uma clara separação entre as diversas formas de cultura. A cultura legitimada e reconhecida era chamada de "cultura letrada", ou "alta cultura", manifestada pela produção intelectual, a partir do século XIII, por meio do conhecimento universitário. Por outro lado, existia o conceito de cultura popular, que remetia às festas, às lendas e ao folclore, e era passada de forma oral, de geração a geração, por meio de símbolos e de narrativas. Com o avanço da técnica e da produção em larga escala, moldou-se a chamada "cultura de massa".

Em um mundo altamente globalizado e interconectado, abundam novas formas de nos relacionarmos uns com os outros, já que somos, mais do que nunca, mediados pelas tecnologias. A modernidade e o estreitamento de fronteiras ampliaram as formas de comunicação e de interação. Atualmente, é possível conectar-se com pessoas no mundo todo de forma instantânea. Os fluxos migratórios, a difusão tecnológica e as novas mídias potencializaram o hibridismo cultural, que, de acordo com Burke (2013, p. 27), se faz presente em diversos segmentos culturais, como música, literatura, culinária, arquitetura, esporte, festas e, até mesmo, nos textos. Um dos exemplos de artefatos híbridos consiste nas traduções, pois, um livro, ao ser editado em outro idioma, obtém uma ressignificação em um novo contexto cultural, já que a adaptação de língua muda o seu sentido original.

Além disso, as metrópoles e as fronteiras constituem espaços geográficos fundamentais, visto que contribuem na troca cultural e na hibridização de diferentes grupos étnicos. Segundo Burke (2013, p. 70-73), grandes cidades, como São Paulo, Nova Iorque, Londres e Mumbai, constituem exemplos de metrópoles marcadas pela grande presença de imigrantes. As zonas fronteiriças são locais de encontro e também de intersecções entre culturas, ou seja, vivemos uma nova ordem cultural global heterogênea, diversificada, que se adapta a diferentes ambientes. 
Canclini (1998) explica que as dicotomias (como, por exemplo, o tradicional e o moderno, a alta cultura e a cultura popular), precisam ser repensadas:

Assim como não funciona a oposição abrupta entre o tradicional e o moderno, o culto, o popular e o massivo não estão onde estamos habituados a encontrálos. É necessário demolir essa divisão em três pavimentos, essa concepção em camadas do mundo da cultura, e averiguar se sua hibridação pode ser lida com as ferramentas das disciplinas que os estudam separadamente: a história da arte e a literatura que se ocupam do "culto"; o folclore e antropologia, consagrados ao popular, os trabalhos sobre comunicação, especializados na cultura massiva. Precisamos de ciências sociais nômades, capazes de circular pelas escadas que ligam esses pavimentos. Ou melhor: que redesenhem os níveis horizontalmente. (CANCLINI, 1998, p. 19).

Canclini (1998, p. 285) sugere que a expansão urbana consiste em uma das causas que intensificam a hibridação cultural, à medida em que as comunidades rurais se modificam a partir do contato com outras culturas e formas de comunicação e de interação. São redes nacionais e transnacionais de comunicação, isto é, as culturas já não se agrupam mais em grupos fixos e estáveis.

Pode-se dizer que, atualmente, todas as culturas são de fronteira e, por isso, adquirem novos significados e interagem com diversos campos, contribuindo em novos conhecimentos:

As hibridações descritas ao longo deste livro nos levam a concluir que hoje todas as culturas são de fronteira. Todas as artes se desenvolvem em relação com outras artes: o artesanato migra do campo para a cidade; os filmes, os vídeos e canções que narram acontecimentos de um povo são intercambiados com outros. Assim as culturas perdem a relação exclusiva com seu território, mas ganham em comunicação e conhecimento (CANCLINI, 1998, p. 348).

\section{CULTURA DA MÍDIA E OS PROCESSOS SIMBÓLICOS DA TELEVISÃO}

A mídia é fundamental para a sociedade, pois participa da nossa vida social e cultural contemporânea. Silverstone (1999, p. 16) explica que a mídia pode ser classificada como um processo no qual os indivíduos — independente de estar no espaço real ou virtual — procuram persuadir, informar, entreter, educar e conectar-se uns com os outros. A mídia, por meio de suas representações e construções de significados, filtra e molda realidades do cotidiano das pessoas; tais representações servem como referência para a 
condução de suas vidas, além da manutenção do senso comum e da definição de identidades.

Douglas Kellner, em A cultura da mídia. Estudos culturais: identidade e politica entre o moderno e o pós-moderno (2001) afirma como atuam as representações:

Numa cultura da imagem dos meios de comunicação de massa são as representações que ajudam a construir a visão de mundo do indivíduo, o senso de identidade e sexo, consumando estilos e modos de vida, bem como pensamentos e ações sociopolíticas (KELLNER, 2001, p. 82).

As narrativas e as imagens promovidas pelos diversos meios de comunicação, como os jornais, o rádio, as revistas, a televisão e a internet, auxiliam na construção de símbolos que trabalham com sentidos, ideias e emoções.

A cultura da mídia constitui uma cultura bigh-tech, que acompanha o desenvolvimento da tecnologia. Os meios de comunicação tendem a adaptar-se às novas tendências tecnológicas. Para Kellner (2001, p. 20): “é um modo de tecnocultura que mescla cultura e tecnologia em novas formas e configurações, produzindo novos tipos de sociedade em que mídia e tecnologia se tornam princípios organizadores".

Um dos meios de comunicação que vêm mostrando mudanças significativas em sua configuração e forma de transmissão é a televisão (último meio tradicional a desenvolver-se), que constitui um resumo de texto, som e imagens em movimento. Apesar da chegada da internet, a TV ainda é o meio mais utilizado entre os brasileiros. O tempo médio gasto com a TV, por dia, é de quatro horas e vinte e oito minutos. ${ }^{1}$

Outro dado que mostra a influência da televisão na sociedade é o que diz respeito às personalidades mais influentes do Brasil. No topo da lista de uma pesquisa recente, realizada pela Provokers para Google e Meio \& Mensagem, consta um apresentador da Rede Globo. Já no ranking das dez celebridades mais influentes, cinco são da TV e, as outras cinco, youtubers. ${ }^{2}$

Mas o que há de tão "sedutor" na tela da TV? O autor Giuseppe Mininni, na obra Psicologia da Mídia, abre alguns caminhos sobre essa questão.

Mininni (2008, p. 82) mostra que grande parte do fluxo de "notícias"

\footnotetext{
Pesquisa revela preferências dos brasileiros em relação ao consumo de mídia, por José Borghi, da Mullen Lowe. Exame, 18 de maio de 2016, Acessível em: http://exame.abril.com.br/negocios/dino/ preferencias-dos-brasileiros-em-relacao-ao-consumo-de-midia-por-jose-borghi-da-mullen-lowe-dino89095184131/. Acessado em 03.12.2016

2 Os mais influentes da internet e da TV. Meio \& Mensagem, 30 de setembro de 2016, Acessível em: http://www.meioemensagem.com.br/home/midia/2016/09/30/as-personalidades-mais-influentesda-internet-e-da-tv.html. Acessado em: 03.12.2016
} 
e "relações" nos quais estamos envolvidos hoje passa pela visão: da escrita, às artes plásticas; do teatro, à gráfica; das histórias em quadrinhos, ao cinema e à televisão. No entanto todos esses modos de comunicar são bastante diferentes entre si, pois cada um possui uma forma de organização interna que corresponde a processos psicológicos distintos. A televisão e o cinema diferenciam-se dos demais, já que estabelecem novos nexos de informação sensorial tanto auditivos, quanto visuais. Atraem grandes massas de usuários, consentindo-lhes novas formas de consumo simbólico, exibindo um tipo de linguagem marcada pelo aceleramento da experiência.

Diferentemente de uma pintura, ou de uma fotografia, artes estáticas - nas quais é necessário um tempo maior para obervar, apreciar e absorver o sentido - , na televisão, ou no cinema, as imagens moventes apresentam narrativas que dialogam com nosso repertório cultural, facilitando a compreensão. A comunicação audiovisual prende a atenção de forma mais imediata do que outros sistemas de signos:

Do ponto de vista funcional, a comunicação audiovisual atende às principais necessidades das pessoas e dos grupos, fornecendo-lhes oportunidades de informação, de entretenimento e de identificação social. A forma geral de aculturação resultante disso é centrada na imagem, da qual deixa transparecer tanto a foça (síntese expressiva, fascínio persuasivo etc.) quanto a fraqueza (ambiguidade interpretativa, padronização etc.). A imagem consegue prender a atenção de forma mais imediata e sedutora do que os outros sistemas de signos, pois fornece uma síntese de informações que parece autorizar a rapidez da primeira interpretação emocional (MININNI, 2008, p. 83).

A inauguração da TV no Brasil ocorreu em 18 de setembro de 1950 e, de acordo com Melo, (2010, p. 27-28) o nascimento TV latino-americana foi tardio, se comparado aos países da Europa e aos EUA, nos quais a televisão já existia nas décadas de 1930 e de 1940. Em nosso país, o mercado de TV era limitado e surgiu pelo voluntarismo do empresário Assis Chateaubriand, proprietário de um conglomerado multimídia espalhado por todo o território nacional. O empresário firmou, em 1948, contrato com a RCA para adquirir equipamentos básicos e enviou engenheiros da sua companhia para estagiar na rede NBC, em Nova Iorque. Nessa época, na qual a televisão era destinada à elite, a empresa importou duzentos televisores, distribuídos, estrategicamente, em vários pontos da cidade de São Paulo, para motivar a recepção dos programas e conquistar futuros telespectadores.

Melo (2010, p. 30) explica que, nessa época, o modelo brasileiro de televisão se caracterizava pela interconexão entre o Estado paternalista e os 
grupos econômicos presentes no negócio da mídia. A programação continha filmes, desenhos animados e show de variedades importados dos EUA, além de produções nacionais, como noticiários, esportes, musicais, shows de auditório e telenovelas. Os programas eram gerados nas cidades de São Paulo e Rio de Janeiro.

A partir da década de 1980, a televisão brasileira tornou-se mais acessível e, ao mesmo tempo, passou a disseminar mais mensagens publicitárias. Com isso, os empresários começaram a investir na melhoria da qualidade da programação.

A primeira a avançar nesse sentido foi a Rede Globo, que ingressou no negócio da televisão somente no início da década de 1960, apesar de já possuir, desde alguns anos antes, um canal concedido pelo governo (Melo, 2010, p. 33). Esse momento coincidiu com o declínio da Rede Tupi. A Globo buscou, no mercado internacional, uma parceria com a Time Life para suprir suas carências mercadológicas e tecnológicas. O acordo foi anulado depois de uma grande polêmica suscitada pelo Governo Nacional, mas, mesmo assim, não foi difícil para a Rede Globo conquistar a hegemonia na televisão brasileira durante décadas. Princípios gerenciais, vontade política da empresa, investimento em tecnologia e pesquisa, criatividade artística e o apoio do governo militar são alguns dos fatores que contribuíram para a construção desse monopólio televisivo. Um dos elementos fortes da Rede Globo é a telenovela, que se tornou um produto típico da cultura de massas (Melo, 2010, p. 64), já que, nelas, o cidadão comum encontra as tramas envolventes, se identifica com as narrativas e com os personagens, projetando-se naquele mundo, como se também dele participasse. Ele se transporta para outra realidade, alimentando seu imaginário, que, de acordo com Cunha (2012, p. 38), engloba tudo aquilo que se apreende e é elaborado de forma coletiva, relacionando-se às expressões culturais. O imaginário é modificado conforme a identidade de cada sujeito e também a partir do que cada cultura produz. O imaginário social constrói, tensiona e ressignifica as culturas. Dessa forma, criam-se novas significações imaginárias; as imagens medeiam intercâmbios, encontros culturais e identidades. Como se vê, os processos comunicacionais são parte da dinâmica social.

\section{TECNOLOGIA E CONVERGÊNCIA DAS MÍDIAS}

Os meios de comunicação constituem produtos socioculturais, porém são, também, produtos técnicos; passam por transformações, impactando, diretamente, as formas de organização, de transmissão de mensagens e os processos de interação entre as pessoas. A forma como nos relacionamos vem sofrendo mudanças ao longo dos anos, sobretudo a partir do surgimento 
da Internet. Cibercultura, ciberespaço, comunidades virtuais e redes sociais digitais constituem expressões cada vez mais comuns.

Pierre Lévy (1999, p. 23) lembra que as técnicas carregam, consigo, projetos, esquemas imaginários e implicações socioculturais bastante variadas. Sua presença e seu uso podem conduzir a relações de força sempre diferentes entre os seres humanos. Além disso, o ciberespaço acompanha, traduz e favorece a evolução geral da civilização. Uma técnica é produzida dentro de uma cultura e uma sociedade encontra-se condicionada por suas técnicas.

Castells (2003, p. 8) destaca a importância da relação entre a comunicação e a internet: "a internet é um meio de comunicação que permite, pela primeira vez, a comunicação de muitos com muitos, num momento escolhido, em escala global".

Todos os domínios da vida social têm sofrido alterações com a Internet, desde a forma mais simples de pesquisar conteúdos em sites de busca, até as trocas comunicacionais, tais como o e-mail, as redes sociais, os aplicativos e assim por diante. Consequentemente, as mídias tradicionais também se vêm adaptando aos meios digitais, visto que investem na produção de web rádios, de web TVs, de jornais e revistas online etc.

Retomando a questão da televisão, que é a nossa proposta, Lévy (1999) mostra-nos que esse aparelho constitui um tipo de mídia que lida com imagens rápidas e que, no passado, o papel do telespectador era apenas o de ser passivo e envolver-se emocionalmente com o espetáculo:

A televisão, interagindo com as outras mídias, faz surgir um plano de existência emocional que reúne os membros da sociedade em uma espécie de macrocontexto flutuante, sem memória, em rápida evolução. O que pode ser percebido particularmente nos fenômenos da transmissão "ao vivo" e, em geral, quando as notícias são quentes [...]. A principal diferença entre o contexto midiático e o contexto oral é que os telespectadores, quando estão implicados emocionalmente na esfera do espetáculo, nunca podem estar implicados praticamente. Por construção, no plano da existência midiática, jamais são atores (LÉVY, 1999, p. 119).

No entanto, a partir da Internet, da TV digital e da convergência entre as mídias, esse cenário vem mudando. O telespectador tem muito mais autonomia para escolher o programa e o horário em que quer assistir a ele, se quer pausar, ou assistir novamente, e até mesmo montar sua grade horária. Além disso, não depende mais do aparelho fixo na sala onde a família se costumava reunir.

O usuário pode acessar filmes, séries e diversas atrações por meio de sites, de aplicativos, dentre outras plataformas digitais. Acreditava-se que 
as novas mídias substituiriam, ou excluiriam, as antigas. Todavia, de acordo com Henry Jenkis, em Cultura da Convergência (2008), os mercados midiáticos passam por uma mudança de paradigma:

Se o paradigma da revolução digital presumia que as novas mídias substituiriam as antigas, o emergente paradigma da convergência presume que novas e antigas mídias irão interagir de forma cada vez mais complexa [...]. A convergência é, nesse sentido, um conceito antigo assumindo novos significados (JENKINS, 2008, p. 32-33).

Para Jenkins (2008, p. 44), a convergência envolve uma transformação tanto na forma de produzir, quanto na de consumir os meios de comunicação. Isso porque, a partir do momento em que as mídias adquirem um caráter híbrido, no qual é possível assistir a vídeos em meio aos textos e às imagens, em um único aparelho, as formas de recepção também mudam. No passado, tudo era bem separado e distinto.

Como explica Santaella (2003), na produção cultural, os meios de comunicação também desempenham a função de meios de difusão. Os meios não "acabam" por si só, mas mudam de suporte:

O livro não desapareceu com a explosão do jornal, nem deverão ambos, livro e jornal, desaparecer com o surgimento das redes teleinformáticas. Poderão, no máximo, mudar de suporte, do papel para a tela eletrônica, assim como o livro saltou do couro para o papiro e deste para o papel. Os meios industriais também não desapareceram para ceder lugar aos eletrônicos, assim como estes não deverão desaparecer frente ao advento dos meios teleinformáticos. [...] A tendência que se pode prever é a das novas alianças, como aquela que se anuncia da TV digital, interativa com o computador e as redes de telecomunicação (SANTAELLA, 2003, p. 57).

HIBRIDISMO TECNOLÓGICO NO AUDIOVISUAL: O CASO DO PROGRAMA DE TV "O MUNDO SEGUNDO OS BRASILEIROS"

O hibridismo cultural é um conceito trabalhado por Canclini e por Burke, dentre outros autores ${ }^{3}$. No entanto o hibridismo constitui campo amplo, que se pode aproximar da tecnologia. Como exposto anteriormente, a convergência das mídias permite que um produto audiovisual possa ser transmitido em diversos suportes. Um exemplo disso é o programa de TV O

Recomendamos: BHABHA, H. K. O local da cultura. 2 ed. Belo Horizonte: Editora UFMG, 2013 e HALL, S. Da diáspora: identidades e mediações culturais. Belo Horizonte: Editora UFMG. 2006. 
Mundo Segundo os Brasileiros, que mostra dicas de roteiros turísticos e é exibido semalmente, às sextas-feiras à noite, pela Rede Bandeirantes. O programa de entretenimento estreou em 2011, tem alcance nacional e está em sua sexta

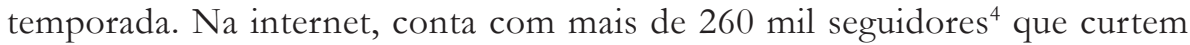
a página no Facebook. É possível assistir aos episódios pelo Youtube e pelo serviço sob demanda Netflix.

Nesse momento, percebemos que a televisão se reinventa junto aos avanços tecnológicos, pois o programa de TV perpassa o aparelho e migra para outras plataformas audiovisuais. Além disso, podemos observar alguns elementos que compõem o hibridismo no programa: (1) suporte tecnológico: indica uma mistura entre televisão, site de vídeos online e serviço sob demanda; (2) gênero televisivo: infotainment ${ }^{5}$, embora seja voltado ao entretenimento, o programa possui um caráter informacional por apresentar dicas de locais turísticos e explicar o contexto histórico de locais públicos importantes, praças e monumentos; (3) cultural: brasileiros que moram em outros países mantêm seus costumes, adquirem os costumes estrangeiros ou mesclam as duas culturas. (4) documental: mostra relatos de personagens reais que contam suas histórias de vida por elas mesmas e não por intermédio de um narrador fixo, ou de algum produtor do programa.

As narrativas são elementos fundamentais da comunicação e estão presentes nos nos programas de TV. As de viagem, especificamente, sejam a lugares próximos, sejam a locais distantes - além de transcender o tempo e o espaço - , despertam, no ser humano, a sensação ancestral de estar frente ao desconhecido e, com isso, mobilizam profundos conteúdos psíquicos, que permitem aflorar percepções e inovações até então adormecidas nos indivíduos e na espécie humana (JUNG, 2000 apud MARTINEZ, 2012).

Os Estudos Culturais já nos mostraram o quanto é importante analisar os artefatos culturais e midiáticos consumidos pelos indivíduos para compreender como as redes de significados são construídas socialmente. Como lembra Escosteguy (1998, p. 87): “se originalmente os Estudos Culturais foram uma invenção britânica, hoje, na sua forma contemporânea, transformam-se num fenômeno internacional".

\footnotetext{
4 Em https://www.facebook.com/omundosegundoosbrasileiros/?fref=ts. Acessado em 04.12.2016. ${ }^{5}$ TARAPANOFF, F. P. A. Infotainment: hibridismo de gêneros. In: XVII CONGRESSO DE CIÊNCIAS DA COMUNICAÇÃO, 2012, Ouro Preto. Anais eletrônicos... Ouro Preto, Intercom, 2012. Disponível em: < http://www.intercom.org.br/papers/regionais/sudeste2012/resumos/R33-2026-1.pdf > Acessado em: 04.12.2016.
} 


\section{CONCLUSÕES}

A revolução da técnica provocou, não somente uma mudança na comunicação e nas mídias, mas também a possibilidade de as tecnologias e os aparelhos expandirem a mente humana.

Mas qual será o futuro da TV, uma vez que ela se transforma e se adapta às novas tecnologias? Sebastião Squirra (2013) explica:

Isso afeta contundentemente a televisão, tanto como negócio quanto como setor de difusão de entretenimento e cultura, pois se constata que a profunda tecnologização dos processos de acesso e usufruto dos produtos midiáticos dos dias atuais rompeu com mais de seis décadas de irrecusável hegemonia do aparelho de televisão como elemento básico para a integração dos seres (SQUIRRA, 2013, p. 23).

Ou seja, a forte estrutura construída e mantida em torno da televisão, ao longo de décadas, sofre com a chegada da realidade digital, o que provoca uma grande mudança nos hábitos de consumo de cultura e de entretenimento nas mídias. Como consequência, as práticas comunicacionais alteraram-se radicalmente.

De acordo com Squirra (2013) o próprio termo “telespectador" está em declínio, já que o espectador não é mais o sujeito que assiste passivamente aos programas em tempo real. Hoje, esse usuário tem autonomia para assistir o que, como e quando quiser e faz o download para a sua máquina pessoal portátil:

Essa possibilidade constitui-se como uma irrefutável revolução nos hábitos comunicativos e é uma oportunidade inédita na história do homem, pois o mesmo nunca tinha sido o autor principal dos enunciados televisivos e, sim, um simples e silencioso consumidor desses processos (SQUIRRA, 2013, p. 93).

Nesse contexto, podemos concluir que se praticam várias comunicações, isto é, migra-se do formato tecnológico limitado às possibilidades inéditas da multicomunicação, na qual se fundem mídias dinâmicas e imediatas. Como afirma Squirra (2013, p. 94): "é a comunicação dentro da comunicação, pois são canais de comunicação em várias esferas".

A pós-modernidade, o avanço das tecnologias e a convergência das mídias permitiu um novo cenário na comunicação e na cultura. A televisão, antes vista como um meio fixo, cuja transmissão era reproduzida por um único aparelho e um único emissor, sofre alterações em sua essência.

O hibridismo perpassa o campo da antropologia e das artes e atinge novas configurações, como é o caso da tecnologia e das mídias. Atualmen- 
te, podemos pensar em um novo contexto muito mais complexo de fluxos, hibridações e interações tanto na cultura, quanto na comunicação:

As instabilidades, interstícios, deslizamentos e reorganizações constantes dos cenários culturais, a circulação mais fluida e as articulações mais complexas, as interações e reintegrações dos níveis, gêneros e formas de cultura, o cruzamento de suas identidades, a transnacionalização da cultura, o crescimento acelerado das tecnologias e das mídias comunicacionais, a ampliação dos mercados culturais, a expansão e os novos hábitos no consumo de cultura estão nos desafiando para encontrar novas estratégias e perspectivas de entendimento, capazes de acompanhar os deslocamentos e as contradições, os desenhos móveis de heterogeneidade pluritemporal e espacial que caracteriza as sociedades pós-modernas, muito acentuadamente as latino-americanas (SANTAELLA, 2003, p. 65).

\section{REFERÊNCIAS}

BURKE, P. Hibridismo cultural. Porto Alegre: UNISINOS, 2003.

CANCLINI, N. G. Culturas híbridas. São Paulo: Edusp, 1998.

CASTELLS, M. A galáxia da Internet: reflexões sobre a internet, os negócios e a sociedade. Rio de Janeiro: Jorge Zahar, 2003.

CUNHA, M. N. Da imagem, à imaginação ao imaginário: elementos-chave para os estudos de comunicação e cultura. In: BARROS, L. M. (Org). Discursos Midiáticos: representações e apropriações culturais. São Bernardo do Campo: Editora Metodista, 2012, p. 33-48.

ESCOsteguY, A. C. Uma introdução aos Estudos Culturais. Revista FAMECOS. Porto Alegre. v.1, n.9, p. 87-97, dez.1998. Disponível em: < http://revistaseletronicas.pucrs.br/ojs/index.php/revistafamecos/ article/view/3014/2292> Acesso em: 29 nov.2016.

JENKINS, H. Cultura da convergência. 2 ed. São Paulo: Eleph, 2009.

KELLNER, D. A cultura da mídia. Estudos culturais: identidade e política entre o moderno e o pósmoderno. Bauru: EDUSC, 2001.

LÉVY, P. Cibercultura. São Paulo: Editora 34, 1999.

MININNI, G. Psicologia cultural da mídia. São Paulo: Edições Sesc, 2008.

MARTINEZ, M. Narrativas de viagem: escritos autorais que transcendem o tempo e o espaço. Revista Brasileira de Ciências da Comunicação. São Paulo. v.35, n.1, p.34-52, jan./jun. 2012. Disponível em: http://www.scielo.br/pdf/interc/v35n1/03.pdf. Acesso em: 10 nov.2016.

MARTINO, L. M. Teoria da comunicação: ideias, conceitos e métodos. São Paulo: Vozes, 2009.

MELO, J. M. de. Televisão brasileira: desenvolvimento, globalização, identidade. 60 anos de ousadia, astúcia e reinvenção. São Bernardo do Campo: Editora Metodista, 2010. 
Teorias da Comunicação: paradigmas latino-americanos. Petrópolis: Vozes, 1998.

SANTAELLA, L. Culturas e artes do pós-humano: da cultura das mídias à cibercultura. São Paulo: Paulus, 2003.

SilVerstone, R. Por que estudar a mídia. São Paulo: Loyola, 2002.

SQUIRRA, S. A iComunicação: da metacomunicação à Ciberlogia. Revista Iberoamericana de Ciencias de la Comunicación. n 2, ISSN 2182-7095, p. 86-97, Ago. 2013, Disponível em

$<$ https://issuu.com/editora-arca-dagua/docs/ibero1> Acesso em: 30 nov. 2016.

. O futuro da TV na fusão tecnológica que tudo altera. Revista de Rádiodifusão. São Paulo, v.07, n.07, p. 21-27, 2013. Disponível em: < http://set6.tempsite.ws/revistaeletronica/index.php/ revistaderadiodifusao/article/viewFile/77/85> Acesso em: 30 nov. 2016.

WOLTON, D. Informar não é comunicar. Porto Alegre: Sulina, 2010. 